\title{
The effect of graphing calculator use on learners' achievement and strategies in quadratic inequality problem solving
}

\begin{tabular}{|c|c|}
\hline \multicolumn{2}{|c|}{$\begin{array}{l}\text { Authors: } \\
\text { Levi Ndlovu }{ }^{1} \text { (D) } \\
\text { Mdutshekelwa Ndlovu }{ }^{2} \text { (D) }\end{array}$} \\
\hline \multicolumn{2}{|c|}{$\begin{array}{l}\text { Affiliations: } \\
\text { 'Stellenbosch University } \\
\text { Centre for Pedagogy, } \\
\text { Department of Curriculum } \\
\text { Studies, Faculty of Education, } \\
\text { Stellenbosch University, Cape } \\
\text { Town, South Africa }\end{array}$} \\
\hline \multicolumn{2}{|c|}{$\begin{array}{l}{ }^{2} \text { Department of Science and } \\
\text { Technology Education, } \\
\text { Faculty of Education, } \\
\text { University of Johannesburg, } \\
\text { Johannesburg, South Africa }\end{array}$} \\
\hline \multicolumn{2}{|c|}{$\begin{array}{l}\text { Corresponding author: } \\
\text { Levi Ndlovu, } \\
\text { ndlovulevi@yahoo.com }\end{array}$} \\
\hline \multicolumn{2}{|c|}{$\begin{array}{l}\text { Dates: } \\
\text { Received: } 30 \text { Apr. } 2020 \\
\text { Accepted: } 08 \text { Oct. } 2020 \\
\text { Published: } 18 \text { Nov. } 2020\end{array}$} \\
\hline \multicolumn{2}{|c|}{$\begin{array}{l}\text { How to cite this article: } \\
\text { Ndlovu, L., \& Ndlovu, M. } \\
\text { (2020). The effect of graphing } \\
\text { calculator use on learners' } \\
\text { achievement and strategies } \\
\text { in quadratic inequality } \\
\text { problem solving. Pythagoras, } \\
41(1), \text { a552. https://doi. } \\
\text { org/10.4102/pythagoras. } \\
\text { v41i1.552 }\end{array}$} \\
\hline \multicolumn{2}{|c|}{$\begin{array}{l}\text { Copyright: } \\
\text { ( 2020. The Authors. } \\
\text { Licensee: AOSIS. This wo } \\
\text { is licensed under the } \\
\text { Creative Commons } \\
\text { Attribution License. }\end{array}$} \\
\hline Read online: & \\
\hline 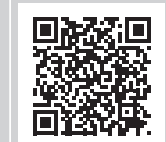 & $\begin{array}{l}\text { Scan this QR } \\
\text { code with your } \\
\text { smart phone or } \\
\text { mobile device } \\
\text { to read online. }\end{array}$ \\
\hline
\end{tabular}

The purpose of this mixed methods study was to investigate the effect of a graphing calculator (GC) intervention on Grade 11 learners' achievement in quadratic inequality problem solving. The quantitative aspects of the study involved an experimental and control group design in which the experimental group received instruction using the GC activities and the control group was taught without using the GC. The qualitative aspects of the study involved script analysis and task-based interviews. We used three data collection instruments: a quadratic inequality problem solving test used both as a pre- and a post-test administered to both the experimental and the control group learners, a written task analysis protocol and a task-based interview schedule. The results of the dependent samples $t$-test confirmed a statistically significant improvement in the quadratic inequality problem solving achievement of the experimental group with a Cohen's $d$ effect size of 1.3. The dependent $t$-test results for the control group were also a statistically significant improvement but with a smaller Cohen's $d$ of 1.2. The results of the independent $t$-test indicated that the experimental group achievement was significantly higher than that of the control group with a Cohen's $d$ effect size of 0.79. Script analysis of selected learners' post-test solutions also showed that learners in the experimental group employed more problem-solving strategies (at least three - symbolic, numeric and graphical). Interview results of purposively selected learners also affirmed that experimental group participants perceived the GC intervention to have prepared them more effectively for multiple solution strategies of the quadratic inequality problem tasks. The researchers recommend the integration of GCs in the teaching and learning of mathematics in general and quadratic inequalities in particular. However, more research is needed in the integration of the GC in high-stakes assessment.

Keywords: Quadratic inequality problems; problem-solving strategies; graphing calculator; realistic mathematics learning; learner achievement and strategies.

\section{Introduction}

The mathematical topic of quadratic inequalities plays a significant role in the solution of some real-life optimisation problems as given in the pre-post-test examples of this study. This topic, however, requires prior knowledge of other mathematical topics such as algebra, linear inequalities, quadratic equations, quadratic functions and geometry (Bicer, Capraro, \& Capraro, 2014; El-Khateeb, 2016; Halmaghi, 2011). El-Khateeb (2016) adds that solving inequalities demands basic knowledge of properties and applications of functions that include domain, range and intervals (increasing or decreasing). This implies that the teaching and learning of quadratic inequalities should be underpinned by a strong mathematical background of foundational concepts, algebraic manipulation skills, related contexts of application and geometric visualisation. It is important for learners to understand the relationship of comparison and to develop the competencies of explaining the inequality relations, using terms such as 'greater than', 'less than', 'greater than or equal to', 'less than or equal to', the associated symbolisations $(>,<, \geq, \leq)$ and how all these differ from the relationship of equality $(=)$.

Yin (2005) attests that a sound knowledge of inequalities is critical in the study of engineering, astronomy and science. Civil engineers may, for example, want to design artefacts such as bridges or apply optimisation methods to improve the efficiency or quality of a product. This suggests that proficiency in quadratic inequalities may increase learners' confidence in application and transfer of knowledge to real-life situations (Tsamir \& Bazzini, 2004). Apart from applications in engineering and science, such real-life contexts may also include business, economics and agriculture within the experiential world of learners. Examples may be to maximise profit taking 
into account multiple factors and therefore solutions of systems of inequalities (e.g. linear programming). Learners should thus develop the appropriate mathematical skills of solving inequality problems and interpreting their solutions accurately. The general study of inequalities is also important for the understanding of epsilon-delta proofs in later real analysis studies for those learners who might pursue advanced studies in mathematics. Despite this elaborate rationale for the study of inequalities, high school learners frequently view quadratic inequalities to be one of the most difficult topics in the mathematics curriculum (Bicer et al., 2014; Halmaghi, 2011). These difficulties extend to the solution of quadratic inequalities by learners. As an important topic, the South African Curriculum and Assessment Policy Statement (CAPS) for Mathematics in the Further Education and Training (FET) Phase requires all the learners (Grades 10-12) to study quadratic inequalities and their usefulness in solving real-life problems (Department of Basic Education [DBE], 2011). In this regard, mathematics teachers are at liberty to use digital tools such as graphing calculators (GCs) to enhance the conceptual understanding of quadratic inequalities and reduce conceptual obstacles.

The International Society for Technology in Education (ISTE, 2016) recommends the use of digital technologies, including GCs, to improve the teaching and learning of mathematics. Research also shows that integrating these information and communication technologies (ICTs) also has the potential to develop learners' critical thinking skills and provides them with the opportunity to interpret solutions of inequalities sensibly (Abramovich \& Ehrlich, 2007; Tsamir \& Almog, 2001). Although the use of technology can provide learners with a rich learning environment as advocated by the DBE's (2011) CAPS (intended curriculum), there has not been a widespread adoption of GCs either in the implemented curriculum or in the assessed mathematics curricula of South African high schools.

\section{Problem statement}

Despite the CAPS expressing the desirability for all FET learners to understand quadratic inequalities, the National Senior Certificate (NSC) results contrastingly show that many learners repeatedly have trouble solving inequalities correctly (DBE, 2016, 2018, 2019). From the first authors' experiences Grade 11 learners struggle to understand this topic when introduced to it and seem to rely mainly on rote memorisation of procedures. Learners also have difficulty making connections between quadratic inequalities and their pre-concepts such as linear inequalities and quadratic equations. In addition, learners have difficulty providing meaningful solutions in interval notation, leading to errors regarding the domain and range. They also interpret wrongly the connectives 'and' and 'or' in various problem contexts. As already noted earlier, literature also confirms that many learners experience difficulties when solving quadratic inequality problems in particular (Bicer et al., 2014; Halmaghi, 2011; Verikios \& Farmaki, 2010). From the NSC diagnostic reports (DBE, 2016, 2018, 2019) many learners appear to procedurally treat the inequality as an equation rather than an optimisation problem. This misconception results in inaccurate solutions and consistently limits learners' ability to provide sensible answers (Yin, 2005). Providing learners with relevant or realistic (optimisation) contexts as advocated in Realistic Mathematics Education (RME) might help them make better sense of their answers.

Connecting algebra with functions using a GC is a missing aspect of classroom practice that may help learners to construct more accurate visual representations of quadratic inequalities and their solution sets. The GC's representational affordances appear to have the underexplored potential to meaningfully support, through activity and intertwinement principles of RME, the integration of algebra and functions. For example, learners with difficulties in describing the domain, range, maxima and minima, as well as restricted values, on graphs, including the representation of solution sets by means of the interval notation, might find participation in the GC-enhanced activities more illustrative and therefore more meaningful. In support of this potential, Bicer et al. (2014) argue that working with graphs, algebraic representations and tables of values simultaneously can help learners gain experience that makes their quadratic inequality problem solving more comprehensible.

The function-based approach advocated by Verikios and Farmaki (2010) is a missing link that can be harnessed within the GC environment to more effectively develop learners' contextual quadratic problem-solving strategies and visual thinking skills. Functions of real-life contexts represent horizontal mathematisation instances in RME of which a typical example is the function for the height of an object in free fall: $f(h)=-16 t^{2}+h_{0}$, where $t$ is time in seconds and $h_{0}$ is the initial height in metres. This is one of the gaps that this study sought to fill since the GC is capable of concurrent algebraic, numeric (table of values) and graphic representations. In this study we expected the use of the GC to promote the development of learners' visualisation skills, and meaningful representation and interpretation of quadratic inequality results (Abramovich \& Ehrlich, 2007; Tsamir \& Almog, 2001). We thus reasonably expected the use of the GC to simultaneously mediate the effective teaching and learning of quadratic inequalities embedded in real-life contexts in which the real-world context would serve as a pivot for meaningfulness and relevance of mathematics to real(istic) situations envisaged in RME's characterisation of mathematics as a human activity as articulated in the theoretical framework.

\section{Purpose and research questions}

The purpose of this study was to explore the effectiveness of a GC intervention in the teaching and learning of contextbased quadratic inequalities to Grade 11 learners. To achieve this goal, the study addresses the following overarching research question: To what extent can the use of graphing calculators influence Grade 11 learners' ability to solve quadratic inequality problems embedded in realistic or real-life contexts? 
The following sub-research questions guided this study:

- What is the effect of the pedagogical use of GCs on learners' achievement in solving (contextual) quadratic inequality problems?

- What strategies do learners in a GC-mediated classroom use to solve contextual quadratic inequality problems?

- What are the students' perceptions of (contextual) quadratic inequality problem solving in a GC-mediated classroom?

\section{Literature review}

\section{Research on learners' achievement in solving quadratic inequalities}

Although inequalities are an important mathematics topic, there is limited literature on their teaching and learning in general, particularly quadratic inequalities. This paucity of the literature signifies the persistence of a limited understanding of why learners continue to experience challenges with the topic. Verikios and Farmaki (2010), for example, affirm that not enough research has been conducted with respect to learner's understanding of quadratic inequalities. A better understanding of learners' misconceptions (sources of misunderstanding) can lead to a better understanding of how to teach quadratic inequalities more effectively. Grewal's (1994) study of 311 Grade 12 learners taking higher grade Mathematics in South Africa found that they did not have sufficient prerequisite knowledge, and did not display a satisfactory level of mastery in solving quadratic inequalities. As seen earlier, the development of sufficient prerequisite knowledge may lead to a stronger mastery of quadratic inequality problem solving ability among learners. As seen earlier, Bicer et al. (2014) found that many middle and high school learners in the United States have misconceptions and difficulties regarding quadratic inequality problem solving. They also found that college preservice teachers experienced the same difficulties with solving and interpreting quadratic inequalities accurately. Understanding the difficulties encountered by students can help teachers teach their learners to become better quadratic inequality problem solvers, and more so in a GC-mediated environment. Yin's (2005) single case study found that the learner solved quadratic inequalities procedurally without really coming to grips with concepts like the domain, nor was she able to logically check her answers. This is a problem that a GC-mediated environment can help solve. Also, limiting quadratic inequality problem solving to algorithmic procedures without introducing (optimisation) contexts that are experientially real to students as envisaged in RME might obscure their conception of critical prior knowledge of the domain and range concepts and hinder their ability to check and make proper sense of their answers. In their study, Tsamir and Reshef (2006) investigated whether to present Grade 10 students with a single method or with several methods to solve quadratic inequalities. They introduced the students to three differently sequenced approaches - the sign chart, the graphic and the logical connectives approach - and found that almost all students correctly solved the quadratic inequalities and liked being introduced to different approaches. However, most preferred the graphic approach to the other two methods. Thus, we considered that presenting learners with multiple strategies of solving quadratic inequalities, within a GC intervention, might constitute more effective teaching and learning of the topic. Aided by the use of the GC, the functionbased approach is likely to be more effective. Following Balomenou, Komis and Zacharos's (2017) recommendation on the use of digital tools, this study investigated the efficacy of GC use to fill the research gap in the teaching and learning of quadratic inequalities embedded in realistic contexts. Below we survey literature on the use of the GC in school mathematics education in search of a solution for effective ICT-intensive teaching and learning of quadratic inequalities.

\section{Research on the effect of graphing calculator use in the mathematics classroom}

Early research reveals that GCs significantly affected the teaching and learning of mathematics, particularly functions and graphs (Dunham \& Dick, 1994) and was later expanded to statistics, geometry, trigonometry, algebra, modelling and calculus concepts (Muhundan, 2005). Several researchers report that the use of GCs in mathematics education improves learners' achievement in solving algebra problems in applied contexts, interpreting graphs and general cognitive understanding (e.g. Chen \& Lai, 2015; Karadeniz, 2015; Parrot \& Leong, 2018; Wareham, 2016). This suggests that learners who use GCs can have relative advantage in mathematical problem solving. Additionally, learners using GCs can consistently display more innovation, speed and accuracy in their problem-solving strategies as well as better reasoning in their answers and better visualisation of graphs and abstract concepts (Hunter, 2011; Thomas, 2016). The use of a GC can also potentially improve learners' organisation of written work, and the correct use of notation and symbols (Shahriari, 2019). However, for the successful use of GCs there must be a shift in classroom culture (Parrot \& Leong, 2018), where learners become the constructors of their own mathematical knowledge. This is in line with RME's activity and guided reinvention principles of allowing learners the freedom to become active participants and to reinvent mathematics with the teacher's guidance (Freudenthal, 1991). Ndlovu (2019), for example, states that the created opportunities enabled learners to use visual models, diagrams and symbols for exploring and figuring out the solutions. Rich (1991) also found that GC use changed the classroom dynamics in that learners became more willing to interact, discuss and share their strategies of solving mathematical problems, resulting in improved retention of content. However, this study examined the effect of a GC intervention on the learners' achievement and strategies in quadratic inequality problem solving.

Regarding problem-solving strategies, Kenney (2014) proposed five that are applicable to a GC environment, namely: (1) linking verbal and symbolic representations, (2) recognising conventions and their properties, (3) making connections to symbols and their graphs, (4) linking symbols 
with their numeric representation (e.g. inequalities and tables) and (5) recognising the meaning of symbols within the context of the problem. Kutzler (2000), on the other hand, proposed three strategic steps for solving more complex and real-world problems using the graphing calculator, namely: (1) choosing the model and translating words into the mathematical expressions, (2) applying the available algorithms to solve the model problem and (3) translating the model solution into a real-world solution. These strategies became a core of the activity principle in the RME approach to provide guidance for solving real-world quadratic inequality problems in a GC environment.

\section{RME as a theoretical framework}

We adopted RME as a theoretical framework for this study. RME, developed in the Netherlands for the teaching and learning of mathematics, views mathematics as a human activity in which contextual or experientially real problems are used as the starting points for learning (Drijvers, 2019). It takes a cue from Freudenthal's (1991) advocacy that the learning of mathematics must be experienced as meaningful or authentic sense-making by the learners. In the RME approach, learners are also afforded the opportunity to use their own informal strategies and models to solve problems and to discuss with the teacher and fellow learners (Theodora \& Hidayat, 2018). To this end, RME was relevant as a lens to understand quadratic inequality problem solving in a GCmediated learning environment. We highlight four key constructs in this framework that are applicable to this study, namely the meaning of 'realistic', activity principle, didactic phenomenology and mathematisation (Drijvers, 2019; Ndlovu, 2014; Van den Heuvel-Panhuizen \& Drijvers, 2014).

Realistic in the context of digital tool use in RME means that learners should experience activities with digital technology as meaningful (Drijvers, 2019). That is, the tool must be fit for purpose by helping learners to solve the problems they want or are tasked to solve and produce intelligible representations and results. The activity principle views mathematics as learning by doing, and thus digital tool use ought to give learners opportunities to actively explore, reinvent mathematics and (re)construct their own mathematical understandings as the chief actors (Drijvers, 2019), not as passive observers of the teacher's use. These activities ought to provide learners with experientially real situations that will make them appreciate the purpose and functionality of the digital tools. In this study, learners experienced the use of a GC through the meaningful and purposeful activity of graphing quadratic functions and related quadratic inequalities to produce meaningful solutions (symbolic, numeric and graphic) and to make connections among these.

A didactic phenomenology view of digital tool use means that as the tool gets integrated into the mathematics classroom it can become part of the shared technology-rich classroom discourse that becomes a phenomenon worth studying (Drijvers, 2019). In other words, when digital tools such as GCs and dynamic geometry software become ubiquitous in the classroom their exploratory use for different topics begins to emerge spontaneously. Didactical phenomenology also concerns the analysis of how mathematical thought objects can help to organise and structure phenomena by means of specific activities or concepts (Van den Heuvel-Panhuizen \& Drijvers, 2014). In this case, the teacher may organise the quadratic inequalities (being the phenomena or mathematical objects) into possible instructional activities (or tasks) that support meaningful learning. The same principle provides opportunity for arranging the instructional activities into social groups for learners to collaboratively and interactively discuss their strategies and (re)inventions (Van den Heuvel-Panhuizen \& Drijvers, 2014).

Mathematisation, on the other hand, refers to the activity of doing mathematics (Van den Heuvel-Panhuizen \& Drijvers, 2014). In the horizontal dimension, mathematical procedures are used to organise and solve problems embedded in real-life or realistic contexts. Such procedures include learners being able to schematise, formulate, transform and visualise the realistic or contextual problems mathematically and to transfer knowledge between different domains (Van den Heuvel-Panhuizen \& Drijvers, 2014). This is often referred to as moving from the world of life to the world of symbols which is comparable to mathematical modelling and problem-solving approaches. The vertical dimension entails the solution of a problem, the generalisation of the solution and the further formalisation thereof (Van den Heuvel-Panhuizen \& Drijvers, 2014). This approach uses models, schemes, symbols and diagrams as conceptual tools for developing the mathematical relations. This is often referred to as a transition within the world of symbols from simple to more complex and better organised mental structures or schemes (Van den Heuvel-Panhuizen \& Drijvers, 2014). The digital tool becomes the medium of mathematical expression.

\section{Research methodology}

\section{Research design}

This study used a sequential mixed methods research design to investigate the effects of using a GC on Grade 11 learners' achievement and strategies in quadratic inequality problem solving. The quantitative aspects of the study focused on the classical (teaching) experiment that employed a pre-test-post-test control group design (Creswell, 2011; Laurens, Batlolona, Batlolona, \& Leasa, 2018) to address the first research sub-question. The time allocated for teaching and learning for the two groups was four weeks and the same teacher-researcher taught both groups. In particular, the experimental group was exposed to GC-mediated instruction in quadratic inequalities while the control group was taught using the traditional pen and paper method. The dependent variable in the teaching experiment was learners' achievement in quadratic 
inequality problem solving measured by means of learning gains between the pre-test and the post-test.

In answering the post-test, the experimental group was not allowed to use GCs to determine the solutions because in the NSC examinations candidates are not allowed to bring programmable calculators but they write the same test. We expected that if they had experienced greater learning gains they would demonstrate greater conceptual understanding and perform better than the control group in the post-test. This was also in compliance with the CAPS document, which requires the use of technology to enable learners to create tabular, symbolic and graphical representations (DBE, 2011). Experimental group learners were given adequate time (i.e. a week) to familiarise themselves with the use of the digital tool in the designed activities. Both the experimental and control groups were exposed to Kenney's (2014) and Kutzler's (2000) problem-solving strategies. The control group used more than one pen and paper visualisation method of solving quadratic inequalities (graphical, number line and table). These methods allowed learners to link verbal and symbolic representations to their graphs and solutions. Both groups were given the same learning tasks that required the use of these strategic procedures. The strategies suggested by Kenney and Kutzler assisted in the development of the rubric for assessing the problem-solving abilities of learners in a GC-enhanced classroom.

The qualitative aspects of the study involved script analysis to address the second research sub-question, and task-based interviews to answer the third and final research sub-question.

\section{Participants}

The population for the study consisted of Grade 11 learners in one of the public secondary schools in Gauteng, South Africa. A combination of purposive and simple random sampling strategies was used to select the learner participants for the study. Purposive sampling was used to identify the public high school in Ekurhuleni North district that fell in the underperforming category (as measured by 2016 NSC results of the schools in mathematics). Purposive sampling is a nonrandom method of sampling where the researcher selects information-rich cases for in-depth study (Patton, 2002) and from which the most can be learned (Merriam, 2009). This sampling helps to identify any common patterns of particular interest and value when recording the key experience and shared dimensions of a setting or phenomenon (Patton, 2002). This sampling strategy befits the qualitative aspect as this approach seeks to understand the behaviour of the two groups of learners when solving quadratic inequalities in different classroom environments but in similar school settings.

We drew a random sample of 40 learners from a population of Grade 11 learners doing mathematics at the selected school. The 40 learners were randomly assigned to two groups of 20 learners each. One of the groups served as the experimental group and received GC-mediated instruction as the intervention. The other group served as a control group and received non-GC instruction to develop quadratic inequality problem-solving skills. At the beginning of this study, the two groups wrote the same pre-test at the same time. Approximately four weeks after the administration of the pre-test and completion of the series of intervention lessons, participants of both groups wrote the post-test on contextual word problems of quadratic inequalities to help us answer the first research question. In addition, we drew another random sample of two learners (a boy and girl) from the GC group after the post-test. These learners were interviewed to explore their perceptions of a GC-facilitated learning environment.

\section{Research instruments}

We used three instruments to collect data, namely selfdeveloped quadratic inequality problem solving tests (QIPSTs) to assess problem-solving proficiency, a selfdeveloped assessment rubric for script analysis informed by Kenney's (2014) and Kutzler's (2000) strategies, and a self-developed semi-structured interview schedule to ascertain students' perceptions of the GC-mediated learning environment. The tests were validated by experts prior to the research. Learning gains in quadratic inequality problemsolving proficiency would indicate the effects of the GC intervention within and between the experimental and the control groups.

All the items for the learning activities and the tests were designed using the previous examination question papers and Grade 11 mathematics textbooks about quadratic inequalities. Identical RME-aligned quadratic inequality problems were set for the pre-test and post-test as described below.

Learners were given two quadratic inequality word problems to solve in both the pre-test and post-test as provided below:

1. A small-scale taxi owner's daily profit is given by $\mathrm{f}(x)=-2 x^{2}+70 x$, in which $x$ is the number of trips made per day. Find the number of trips that must be made per day if the profit is to be greater than or equal to R600.

This item used the commercial context of a taxi owner to test whether learners could formulate the corresponding quadratic inequality (ability to distinguish between an equation and an inequality) with a negative coefficient of $x^{2}$ (handling of signs when multiplying by negative values), formulating the inequality correctly (as a maxima problem) from the given word problem, graphing the inequality correctly (as a concave down graphic), as well as interpreting the domain correctly (as a solution set and not a single value). Many working-class students use public transport in South Africa and therefore the context would easily resonate with their daily experiences of commuting to and from school or to and from shopping centres. This formed the realistic context that was experientially real to South African learners (see Figure 1). 


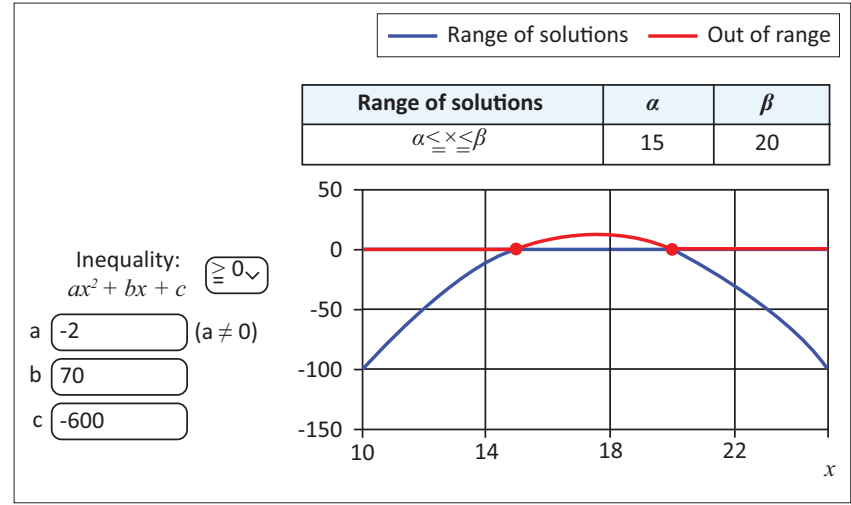

FIGURE 1: Visualisation of solution set for Q1 generated using a graphing calculator.

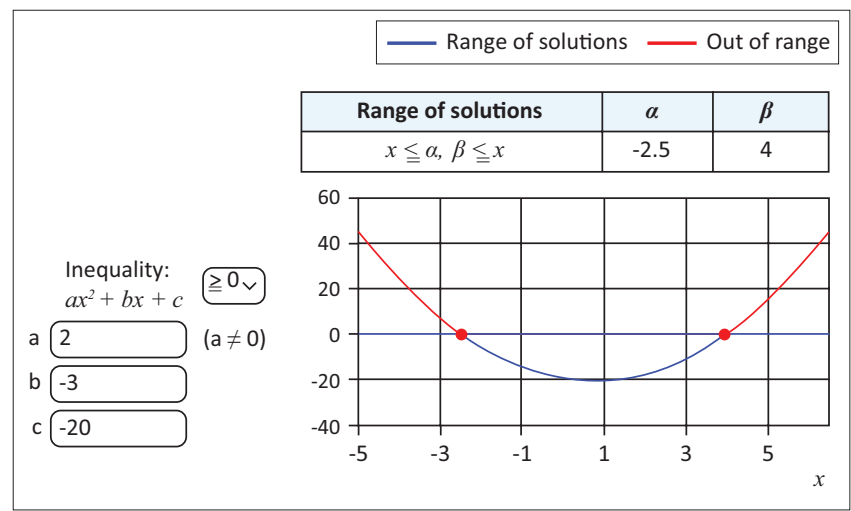

FIGURE 2: Visualisation of the solution set for Q2 generated using a graphing calculator.

2. A small-scale farmer wanted to fence off her chickens within a rectangular area on her farm. The breadth and length are $x$ metres and $2 x-3$ metres. Determine the values of $x$ that can give an area of her chicken run larger or equal to 20 metres $^{2}$.

This small-scale chicken farming context item also tested whether learners could formulate the requisite quadratic inequality (using prior knowledge of the rectangle area formula and ability to distinguish between an equation and an inequality) with a positive coefficient of $x^{2}$ (handling of signs when multiplying by positive values), formulating the inequality correctly (as a minima problem) from the given word problem, graphing the inequality correctly (as a concave up graphic), as well as interpreting the domain correctly (as a solution set and not a single value). Figure 2 is a visualisation of the solution set from the area formula $f(x)=x(2 x-3)=2 x^{2}-3 x$, which leads to the inequality $2 x^{2}-3 x \geq 20$. Many working-class or township school learners eat chicken as one of the cheapest meat types available in South Africa and the context would easily resonate with their daily experiences of not only eating chicken but also how they are raised. This formed the realistic context that was experientially real to South African learners (see Figure 2).

We used at least two markers (the teacher-researcher and a moderator) who obtained similar results using the same rubric. The issue of reliability of the pre-test was also addressed by conducting a pilot study with Grade 11 learners from a different school and both tests were marked by two teachers to compare their scores.

Learners' scripts were scored using the memorandum in the appendix, a modified version of the Analytic Problem Solving Rubric developed by Charles, Lester and O'Daffer (1987) which has been widely used in other problem solving research (Yeo, 2011). The paired samples $t$-test was used to determine the statistical significance of within-group quadratic inequality problem solving learning gains. We used the independent samples $t$-test to determine the statistical significance of the between-group problem solving learning gains attributable to the GC intervention when compared to those of the control group. We calculated Cohen's $d$ using the 2016 Statistical Package for Social Sciences (SPSS) to ascertain the practical significance or effect size of the GC intervention on the experimental group, the non-GC intervention on the control group and to compare both groups. The assessment rubric was used to describe qualitative changes in learners' strategies manifested in the their scripts. We used in-depth interviews to ascertain students' perceptions of the GCmediated learning environment.

\section{Ethical consideration}

The study was approved by Stellenbosch University (ethical clearance/project number: 2023).

\section{Results of the research}

\section{Effect of the GC intervention on learners' achievement in quadratic inequality problem solving}

This section answers the first research question of this study which we broke down into four two-tailed null subhypotheses:

- $\mathbf{H}_{01}$ : There is no difference in the pre-test mean scores of the experimental and control groups, i.e. $\mu_{1}=\mu_{3}$.

- $\mathbf{H}_{02}$ : There is no difference between the pre- and post-test mean scores of the experimental group, i.e. $\mu_{1}=\mu_{2}$.

- $\mathbf{H}_{03}$ : There is no difference between the pre- and post-test mean scores of the control group, i.e. $\mu_{3}=\mu_{4}$.

- $\mathbf{H}_{04}$ : There is no difference in the post-test mean scores of the experimental and control groups, i.e. $\mu_{2}=\mu_{4}$.

$\mu_{1}$ is the experimental group pre-test mean score; $\mu_{2}$ is the experimental group post-test mean score; $\mu_{3}$ is the control group pre-test mean score, and $\mu_{4}$ is the control group posttest mean score.

To test the first hypothesis, we conducted a between-group samples $t$-test using SPSS and the formula:

$$
t=\frac{\bar{X}_{1}-\bar{X}_{2}}{\sqrt{\left(\frac{\left(N_{1}-1\right) s_{1}^{2}+\left(N_{2}-1\right) s_{2}^{2}}{N_{1}+N_{2}-2}\right)\left(\frac{1}{N_{1}}+\frac{1}{N_{2}}\right)}}
$$

The results show that there was no statistically significant difference between the experimental group $\left(\mu_{1}=24.40\right.$; $\mathrm{SD}=14.34)$ and the control group $\left(\mu_{3}=20.05 ; \mathrm{SD}=13.98\right)$ in 
the pre-test since $t=0.97156$ and $p=0.337416$, which is greater than 0.05. This meant that both groups had similar (homogeneous) problem-solving abilities before the GC intervention to the experimental group. It is important to establish the pre-intervention knowledge levels of the experimental and control groups in order to control for preexisting knowledge. This confirmed that random assignment established equivalence between the two groups.

To test the second hypothesis, we conducted a paired samples (within-group) $t$-test using SPSS and the formula:

$$
t=\frac{\frac{\left(\sum D\right)}{N}}{\sqrt{\frac{\sum D^{2}-\left(\frac{\left(\sum D\right)^{2}}{N}\right)}{(N-1)(N)}}}
$$

The results showed a statistically significant improvement in learners' problem-solving abilities of quadratic inequalities from the pre-test $\left(\mu_{1}=24.40, S D_{E}=14.34\right)$ to post-test $\left(\mu_{2}=\right.$ $45.25, S D_{E}=20.65$ ), with $t=5.62$ and $p=0.00002$, which is less than 0.05 , in the experimental group. This meant that there were significant problem solving learning gains in the experimental group. To ascertain the size of the effect we first used Excel to obtain $r=0.602$ and then calculated Cohen's $d$ using G*Power and the formula $d=\frac{\left|\mu_{2}-\mu_{1}\right|}{\sqrt{\left(s_{1}^{2}+s_{2}^{2}\right)-\left(2 r s_{1} s_{2}\right)}}$ to determine whether the difference was practically significant (or big enough to worry about). We obtained a $d$-value of 1.256 (standard deviations), which indicated a large effect size since it is greater than Cohen's (1988) threshold of 0.8 . This meant a practically significantly large improvement of approximately 1.3 standard deviations in the experimental group's (within-group) quadratic inequality problem solving achievement. However, this alone does not tell us whether GC use was more effective than the traditional approach used for the control group.

To test the third hypothesis, we conducted a paired sample (within-group) $t$-test using SPSS and the relevant $t$-test formula for paired samples. The results showed a statistically significant improvement in learners' quadratic inequality problem solving learning gains from the pre-test $\left(\mu_{3}=20.05 ; \mathrm{SD}=13.98\right)$ to the post-test $\left(\mu_{4}=30.6 ; \mathrm{SD}=16.17\right)$, with a $t$-value of 5.30 and $p=0.00004$, which is less than 0.05 , in the control group. To ascertain the size of the effect we first calculated the correlation between the pre-test and the post-test and obtained $r=0.83576$ which we used to calculate Cohen's $d$ of 1.187 which indicated a large effect size since it is greater than Cohen's (1988) threshold of 0.8 . This indicated a large improvement of approximately 1.2 standard deviations in the control group's quadratic problem solving achievement. Hence, not only were learning gains significant in both the experimental and control groups between the pre-test and post-test, but also both groups' learning gains were large. What remains is to establish, by testing the fourth hypothesis, is whether the experimental group's achievement was significantly higher or practically significantly higher than that of the control group. The establishment of this fact is important to show whether the GC intervention in the experimental group was superior to the control group's traditional teaching approach or not since so far both were statistically significant and large. This leads us to the fourth hypothesis.

To test the fourth hypothesis, we conducted an independent samples (between-groups) $t$-test using SPSS and the relevant $t$-test formula for independent samples. We found that the experimental group's post-test mean score $\left(\mu_{2}=45.25\right.$; $\mathrm{SD}=$ $20.65)$ was significantly higher than the control group's mean score $\left(\mu_{4}=30.6 ; \mathrm{SD}=16.17\right)$ since $t=2.49775$ and $p=0.016945$, which is less than 0.05 . To ascertain the size of the difference in effect we computed Cohen's $d$ to determine the magnitude of the differences (effect size) in the means and obtained $d=$ 0.789937. This value was more than the threshold of 0.50 for moderate effect size and marginally short of 0.8 for large effect size (Cohen, 1988). This indicated that the learning gains of the experimental group were more than those of the control group (by a moderate margin of approximately 0.79 standard deviations). That is, learners who used GCs in class became better quadratic inequality problem solvers than those in the control group who used traditional pen and paper methods, albeit by a moderate margin. This means that the experimental group's learning gains were not only statistically significantly higher than those of the control group but also practically significantly superior.

\section{Problem-solving strategies used by learners in the experimental and control groups}

This section answers the second research question: What strategies do the experimental and control groups learners display when solving contextual quadratic inequality problems? An analysis of learners' written responses, in conjunction with the assessment rubric given in Table 1, revealed strategies they used to solve the quadratic inequality problems. Learners' strategies are summarised in Table 2.

TABLE 1: Rubric for quadratic inequality problem solving test.

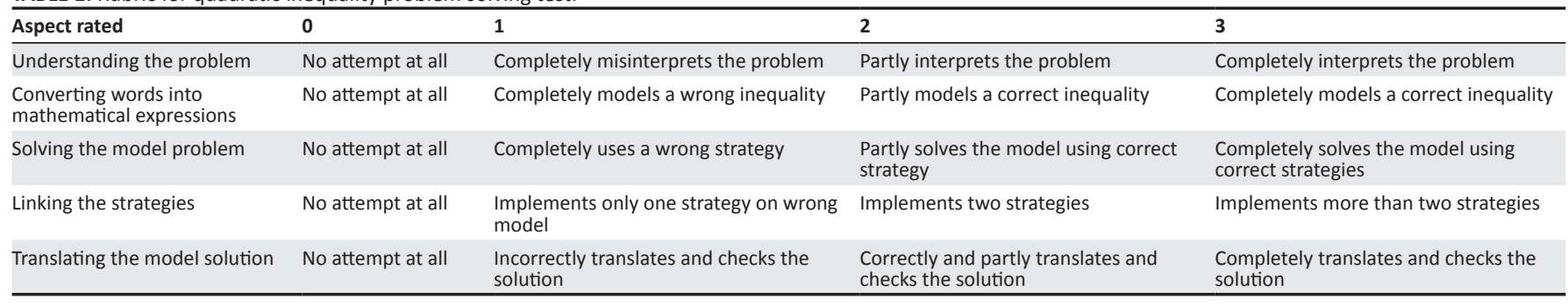


TABLE 2: Frequencies of learners using quadratic inequality problem-solving strategies.

\begin{tabular}{lccccccc}
\hline Group & $\begin{array}{c}\text { Drawing } \\
\text { graphs }\end{array}$ & $\begin{array}{c}\text { Making } \\
\text { tables }\end{array}$ & $\begin{array}{c}\text { Drawing } \\
\text { number } \\
\text { lines }\end{array}$ & $\begin{array}{c}\text { Looking } \\
\text { for } \\
\text { patterns }\end{array}$ & $\begin{array}{c}\text { Factors or } \\
\text { formula }\end{array}$ & $\begin{array}{c}\text { Checking } \\
\text { for } \\
\text { accuracy }\end{array}$ & $\begin{array}{c}\text { No } \\
\text { attempt }\end{array}$ \\
\hline Experimental & 17 & 10 & 9 & 13 & 11 & 13 & 15 \\
Control & 6 & 10 & 11 & 5 & 7 & 8 & 30 \\
\hline
\end{tabular}

Table 2 shows that there was a considerable difference between the two groups in the use of problem-solving strategies. Seventeen (85\%) learners in the experimental group used graphical strategies (i.e. making a model or diagram) while only six (30\%) from the control group did so. The other most frequently used problem-solving strategies by learners from the experimental group were making tables (10 learners, 50\%), looking for patterns (13 learners, 65\%) and checking for accuracy (i.e. logical reasoning; 13 learners, $65 \%$ ). This indicates that learners from the experimental group more often made attempts as evidenced by the way the strategies were distributed.

\section{Learners' perceptions of the GC-mediated quadratic inequality problem solving environment}

This section answers the third research sub-question: What are the learners' perceptions of contextual quadratic inequality problem solving in a GC-mediated environment? In-depth semistructured interviews were conducted with two purposefully selected learners to explore their perceptions of GC use in solving the context-based quadratic inequality problems. To improve readability, we corrected grammatical errors and omitted filler words, but maintained the integrity of the meaning attributable to the interviewees (Oregon Department of Transportation Research Section, 2010). Below are the transcripts involving a female learner, MK (pseudonym), and a male learner, GH (pseudonym):

Teacher-researcher (TR): Does the use of the graphing calculator help you to understand the contextual quadratic inequality problems?

MK: Yes, it did help me to understand the problems of quadratic inequalities.

TR: Please explain how it did help you.

MK: A graphing calculator uses the graphs or number lines to solve the inequalities, which made it easy for me to see where solutions lie.

TR: Does the graphing calculator provide you with opportunities to use more than one method [e.g. table of values, graphs, factors or quadratic formula] in solving quadratic inequality problems?

MK: Yes, it is possible to use more than one method.

TR: Can you explain a little bit.

MK: I used the graphing calculator to calculate the critical values, sketch the graph and then check the solution from the table of values.

TR: Did the graphing calculator use affect your choice of strategies to be applied in solving quadratic inequality problems?

MK: Yes, it does. I never liked using graphs to solve quadratic inequalities but the graphing calculator made me use and enjoy them.
TR: Which of the following strategies were most helpful in solving quadratic inequality problems: graphs, tables, checking, drawings, etc.?

MK: The most helpful strategies for solving quadratic inequality problems are drawing graphs and making table of values.

TR: Using a graphing calculator in quadratic inequality problems does not assist to master the concepts of critical value, interval notation, behaviour of function.

MK: Actually it does because I was able to figure out the behaviour of the function and to use critical values for writing the interval notation.

TR: Does the use of the graphing calculator help you to understand the contextual quadratic inequality problems?

GH: Absolutely yes.

TR: Please explain how it did help you.

GH: Because the graphing calculator shows the quadratic graphs, I was able to figure out the $x$-intercepts and the shape of the graph, and then predict the region of the solution.

TR: Does the graphing calculator provide you with opportunities to use more than one method [e.g. table of values, graphs, factors or quadratic formula] in solving quadratic inequality problems?

GH: Definitely, it allows me to use both graphs, table of values and number lines.

TR: Can you elaborate a little bit.

GH: The graphing calculator use afforded me a chance to work with different methods such as calculating the critical values and deciding the inequality solutions from the sketched graph.

TR: Using graphing calculator does not affect your choice of strategies to be applied in solving quadratic inequality problems.

MK: I think it can affect because I now solve the quadratic inequalities using graphs and number lines that are usually displayed on the graphing calculator. The use of the graphing calculator made me feel more comfortable with graphs.

TR: Which of the following strategies were most helpful in solving quadratic inequality problems: graphs, tables, checking, drawings, etc.?

GH: The most helpful strategies were drawing graphs, number lines and making table of values.

TR: Using a graphing calculator in quadratic inequality problems does not assist to understand the concepts of critical value, domain, interval notation, behaviour of function.

GH: Oh yes, it does assist. I am now able to predict the behaviour of the function and to write domain using correct interval notations.

Learners' responses to the interview were positive and almost similar as they affirmed GC use assisted them to understand quadratic inequality problems better. They responded by saying that GC use 'definitely' and 'absolutely' helped them to 'understand the problem', 'predict the 
behaviour of function' and 'figure out the region of the solution' in quadratic inequalities. This showed that the learners got familiar with the GC environment as envisaged by the activity principle and phenomenological views of ICT tool use in the mathematics classroom. Furthermore, learners indicated that the GC use provided them with opportunities of employing more than one approach to solve quadratic inequalities. This meant learners were able to switch between the various representations with ease and could then have more time to reflect on the reasonableness of their solutions and engage in additional random exploration of the topic tasks. Admittedly, learners indicated that the GC use had an impact on their choices of problem-solving strategies. Both learners mentioned that the availability of the GC inspired them to use graphical strategies and number lines as they are frequently displayed. Through the use of the GC learners were able to master the concepts of critical values, domain, interval notation and graphs. These concepts were critical in determining the solutions of the quadratic inequalities. Using the T1-83 Plus GC, learners can see how the quadratic inequality is solved graphically as displayed on its screen in Figure 3.

In this case, the graph displays the solution set of the quadratic inequality $x^{2}-2 x-3>0$, which is a disjunction of $x=-1$ and $x=3$. The use of the GC, according to the learners, demonstrates the graph with 'its $x$-intercepts which are the critical values' for the inequality. This enabled the learners to visualise the graph with critical values which made it easy to determine the solution of inequalities. The visual images of the graphical representations helped learners to understand easily the connections between the graphs and solutions of quadratic inequalities.

Learners of the control group, in contrast, were exposed to the three methods of solving quadratic inequalities prescribed in the CAPS document (i.e. graphical, table and number line). While the methods have visual aspects, some of the learners mastered the quadratic inequalities through memorising the

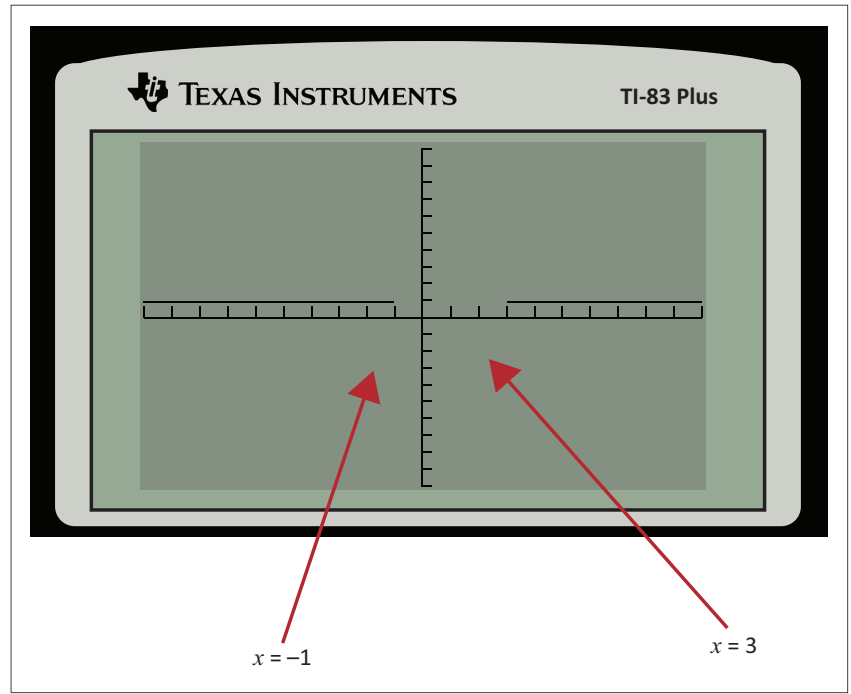

FIGURE 3: Solution of a quadratic inequality displayed on the graphing calculator. procedures. As such, the learners were able to determine the critical values ( $x$-intercepts) of the quadratic expressions but could not write meaningful solutions of the inequalities. Learners further struggled to express their solutions in set builder or interval notations. This is consistent with the findings of the DBE (2018), which indicated that learners treated the inequality as an equation and their solutions did not make sense.

\section{Discussion of results}

In this section we summarise and discuss our findings focusing on the quantitative for researchers who plan to integrate the GC in their classrooms.

\section{Effect of graphing calculator use on learners' quadratic inequality problem solving achievement}

This study addresses the issue of whether GC use affected the learners' achievement and strategies in solving quadratic inequality problems. In this study the GC appeared to be an appropriate instrument for improving learner's achievements. The findings, using an independent $t$-test, showed that there was a statistically significant difference in the mean scores of the post-test for the experimental and control groups. Such findings are compatible with the results obtained in the previous research, which showed that learners exposed to GC-mediated environment can achieve significantly higher scores in problem solving than those who were not (Rich, 1991; Tan et al., 2011). This study adds the case of quadratic inequalities in which RME principles were observed in terms of both the contexts of problems and the integration of the GC, where each learner had access to their own device. The results also support Thomas's (2016) findings that learners who persistently use a GC can achieve more learning gains and be capable of greater flexibility in their problem-solving strategies. Incorporating Kutzler's (2000) and Kenney's (2014) problem-solving strategies into the GC meditated classroom could have led to more systematic experimental group students' involvement in quadratic inequality problem solving activities and more insightful reflection on the effectiveness of their problem-solving strategies. However, not all learners of the experimental group were able to operate the GC in the intended way. Some of them experienced technical and conceptual obstacles leading to 15 'no attempts'. The number of 'no attempts' was, nevertheless, higher (double) for the control group learners. Learners experienced technical difficulties in setting appropriate viewing windows of GCs. They also made some syntactic errors in entering negative numbers with a different minus sign than used for subtraction. This is in line with the previous findings that revealed that the use of GC in teaching and learning often turns out to be more complex than expected (Karadeniz, 2015).

\section{Effect of graphing calculator use on learners' problem- solving strategies in written tasks}

The findings from the learners' written task solutions revealed that there was a difference between the experimental group and control group in the way they answered and 
spread their problem-solving strategies in quadratic inequalities. Despite the fact that the control group was exposed to different visual methods (e.g. graph and number line), they had to memorise some of the necessary procedures to understand the concept. The use of a GC as a visual tool helped learners in the experimental group to intuitively master the properties of algebraic processes, which are missed during the traditional learning process. With the use of a GC, learners can repeat the algebraic processes supported by the visual images and representations. In that regard, the results did show that learners approached questions differently. Specifically, the experimental group consistently used graphical and numerical representations to solve problems and performed better. This is consistent with the results of earlier research, which indicated that using GCs leads to a different distribution of solution strategies, particularly the increased use of graphical strategies (Chen \& Lai, 2015; Harskamp, Suhre, \& Van Streun, 2000). This further shows that GC use remarkably expanded the learners' repertoire of problem-solving strategies to include more visual procedures. This was also supported by other researchers who reviewed that learners become better problem solvers when GCs are used in class (Parrot \& Leong, 2018). This indicates that the GC-supported learning modelled by Kutzler's (2000) and Kenney's (2014) problemsolving strategies afforded learners of the experimental group opportunities to explore quadratic inequality problems by linking strategies such as making a model or diagram, using table of values, linking verbal and symbolic representations and using logical reasoning to infer the meaning within the context of the problem.

\section{Learners' perceptions of graphing calculator use in quadratic inequality problem solving}

The results of the in-depth interviews of the two learners from the experimental group showed that the GC availability had a positive effect on their learning of contextual quadratic inequality problems. In their responses, learners explained that graphing calculators enabled them to use more than one problem-solving strategy (e.g. graph, table of values, number line, etc.). The use of different strategies enhanced the learners' understanding of quadratic inequality problems. This supports the findings obtained by prior researchers (Montijo, 2017; Parrot \& Leong, 2018) reporting that the multiple linked representations provided by a GC in the form of graphic, tabular and computation improved the learners' global view of problem solving. According to Kenney (2014), such problem-solving strategies may be beneficial for learners as they link the algebraic and geometrical affordances. The use of different strategies enabled learners to enjoy and feel comfortable with quadratic inequality problems as they were able to move back and forth among these forms. This is consistent with the results of Parrot and Leong (2018) who found that such representations give learners more time to think about the problem itself without focusing on long algebraic procedures. The results also align with Ndlovu's (2019) findings that the use of a GC increased the learners' confidence in solving more challenging problems.

In addition, the findings showed that learners perceived that GC use affected their choices of problem-solving strategies in quadratic inequalities. The interview results indicate that the consistent use of GC stimulated and increased the learners' application of graphical strategies. This finding is supported by Chen and Lai (2015) who reported that GC use led to changes in the mathematics learners' solution strategies that they employed. We also found that the use of GCs enabled learners to understand and feel comfortable with functional graphs. The indications are that learners mastered well the properties of functions which made it possible for learners to visualise the solutions of the quadratic inequality problems.

These results are consistent with previous studies which indicated that the use of GCs in teaching and learning was helpful to learners' cognitive understanding, visualisation and achievement in mathematics classrooms (Karadeniz, 2015). This is in line with the recommendations of DBE (2018) that integrating algebra with functions can improve learners' visual understanding of quadratic inequalities. This means learners can develop a balance between algebraic solutions and graphical strategies through the use of a GC.

\section{Conclusion}

Information obtained from the results of this research showed that exposing learners to a GC-supported learning environment helped them to improve their achievements and to develop formal problem-solving strategies in quadratic inequalities compared to those who used non-GC methods. The use of a GC created an exceptionally enabling learning environment that became more suitable for learners to be engaged with experimental activities. These experimental activities helped the learners to critically identify the main facts of the problem, to draw its model supported by charts, tables and visual images, and to reflect on the selected strategies of solving quadratic inequalities. The GC served as a tool for integrating algebra with functions so that learners can have a better visual understanding of quadratic inequalities. Using a GC potentially raised learners' cognitive achievement in quadratic inequalities, in particular as they were able to observe the different representations connected to the concept. The varied representations (algebraic, arithmetic, geometric, number pattern) of quadratic inequalities helped learners to gain insight into the big ideas in mathematics. As learners switched between different representations and contexts of the mathematical concept, they were able to realise that such differences in fact are interconnected and interrelated by a single mathematical idea. Such perceptions are critical in raising learners' procedural fluency and applying abstract concepts to concrete real-life mathematical experiences. The idea is that learners who are consistently exposed to GCsupported learning can see the close relationship between concepts and procedures, which is a strong foundation of this 
study to write meaningful interval notations of quadratic inequalities as solution sets.

\section{Recommendations for teachers}

The findings of our research study led us to the following recommendations for teachers who desire to adopt GCsupported lessons in quadratic inequality problems:

- Teachers should consider integrating GCs in teaching and learning of quadratic inequalities as their availability in class can improve learners' academic achievement and solution strategies. This tool, GC, potentially integrates algebra with functions so that learners can have a better visual representation of quadratic inequalities.

- Teachers should consider using GCs in their teaching and learning of quadratic inequalities as learners are afforded opportunities to employ different approaches (graphical, table of values, number line) for increasing the learners' choices of problem-solving strategies.

- Teachers should consider integrating GCs in teaching and learning quadratic inequalities as they increase the use of a graphical approach that enables learners to connect the $x$-intercepts with quadratic inequality solutions. This can help learners to distinguish equations from inequalities.

- Teacher training institutions should assume the lead in developing preservice teachers on how to carefully create a rich learning environment supported by the use of GCs for learners to realise the multiple representations (graphical, symbolic and numeric) of quadratic inequalities.

On the other hand, we recommend that learners should be given more time to use GCs in order to fully master all their key functions and to reduce syntactic errors in entering negative coefficients of quadratic inequalities. This can also help to minimise the technical difficulties experienced in setting appropriate viewing screens or windows of GCs.

It is further recommended that educational policymakers, including universities, must support the drive for progressive changes in the educational approach, in both teachers' and learners' roles in classrooms, where technology is in use. If learners are allowed to use GCs in their assessment, they can have a clear impression of their possible effects on their solution strategies of quadratic inequality problems.

\section{Acknowledgements}

Gauteng Department of Education; Mathematics teachers and principals in Ekurhuleni North district.

\section{Competing interests}

The authors have declared that no competing interest exists.

\section{Authors' contributions}

All authors contributed equally to this work.

\section{Funding information}

This research received no specific grant from any funding agency in the public, commercial or not-for-profit sectors

\section{Data availability statement}

Data sharing is not applicable to this article as no new data were created or analysed in this study.

\section{Disclaimer}

The views and opinions expressed in this article are those of the authors and do not necessarily reflect the official policy or position of any affiliated agency of the authors.

\section{References}

Abramovich, S., \& Ehrlich, A. (2007). Computer as a medium for overcoming misconceptions in solving inequalities. Journal of Computers in Mathematics and Science Teaching, 26(3), 181-196.

Balomenou, A, Komis, V., \& Zacharos, K (2017). Handling signs in inequalities by exploiting multiple dynamic representations - The case of ALNuSet. Digital Experiences in Mathematics Education, 3, 39-69. https://doi.org/10.1007/ s40751-017-0029-9

Bicer, A., Capraro, R.M., \& Capraro, M.M. (2014). Pre-service teachers' linear and quadratic inequalities understandings. International Journal for Mathematics Teaching and Learning. Retrieved from http://www.cimt.plymouth.ac.uk/journal/ default.htm

Charles, R., Lester, F., \& O'Daffer, P. (1987). The analytical scoring scale. How to evaluate progress in problem solving. Reston, VA: National Council of Teachers of Mathematics.

Chen, J.C., \& Lai, Y.N. (2015). A brief review of researchers on the use of graphing calculator in mathematics classrooms. International Journal of Learning, Teaching and Educational Research, 14(2), 163-172.

Cohen, J. (1988). Statistical power analysis for the behavioral sciences. New York, NY: Routledge Academic.

Creswell, J.W. (2011). Educational research: Planning, conducting, and evaluating quantitative and qualitative research (4th edn.). Boston, MA: Pearson.

Department of Basic Education (DBE). (2011). Curriculum and policy statement Grades 10-12. Mathematics. Pretoria: DBE.

Department of Basic Education. (2016). National diagnostic report on learner performance. Pretoria: DBE.

Department of Basic Education. (2018). National diagnostic report on learner performance. Pretoria: DBE.

Department of Basic Education. (2019). National diagnostic report on learner performance. Pretoria: DBE.

Drijvers, P. (2019). Embodied instrumentation: Combining different views on using digital technology in mathematics education. Eleventh Congress of the European Society for Research in Mathematics Education, Utrecht University, Utrecht, 6-10 February.

Dunham, P.R., \& Dick, T.P. (1994). Research on graphing calculators. The Mathematics Teacher, 87(6), 440-445.

El-Khateeb, M.M.A. (2016). Errors analysis of solving linear inequalities among the preparatory year students at King Saud University. Journal of Education and Practice, 7(12), 2016

Freudenthal, H. (1991). Revisiting mathematics education: China lectures. Dordrecht: Kluwer Academic Publishers.

Grewal, A.S. (1994). Concept development in mathematics: Teaching and learning of quadratic equations, inequalities and their graphs. Unpublished thesis of Master of Education, University of Durban-Westville, Durban.

Halmaghi, E. (2011). Undergraduate students' conceptions of inequalities. Doctora dissertation, Simon Fraser University, Burnaby.

Harskamp, E, Suhre, C \& Van Streun, A (2000). Graphics Calculator and Students Solution Strategies. Mathematics Education Research Journal 2000, 12(1), 37-52. Solution Strategies. Mathematics Educat
https://doi.org/10.1007/BF03217073

Hunter, J.S. (2011). The effects of graphing calculator use on high-school students' reasoning in integral calculus. $3463473 \mathrm{Ph}$.D. Ann Arbor, MI: University of New
Orleans. Retrieved from http://search.proquest.com/docview/879337423?accou ntid $=28930$ ProQuest Dissertations \& Theses Global database

ISTE. (2016). Standards for Students. Retrieved from http://www.iste.org/standards/ iste-standards/standards-for-students.

Karadeniz, I. (2015). UCSMP teachers' perspectives when using graphing calculators in advanced mathematics. Graduate theses and dissertations. Retrieved from http://scholarcommons.usf.edu/etd/5712

Kenney, R.H. (2014). Investigating a link between pre-calculus students' uses of graphing calculators and their understanding of mathematical symbols. International Journal of Technology in Mathematics Education, 21(4), 157-166. 
Kutzler, B. (2000). The algebraic calculator as a pedagogical tool for teaching mathematics. International Journal of Computer Algebra in Mathematics Education, 7(1), 5-23.

Laurens, T., Batlolona, F.A., Batlolona, J.R., \& Leasa, M. (2018). How does Realistic Mathematics Education (RME) improve students' mathematics cognitive achievement? EURASIA Journal of Mathematics, Science and Technology Education, 14(2), 569-578. https://doi.org/10.12973/ejmste/76959

Merriam, S.B. (2009). Qualitative research. A guide to design and implementation (2nd edn.). San Francisco, CA: Jossey-Bass.

Montijo, E. (2017). The effects of Desmos and TI-83 plus graphing calculators on the problem-solving confidence of middle and high school mathematics students. Unpublished dissertation of the Degree Doctor of Education, Liberty University, Lynchburg, VA.

Muhundan, A. (2005). Effects of using graphing calculators with a numerical approach on students' learning of limits and derivatives in an applied calculus course at a community college. Graduate theses and dissertations. Retrieved from http:// scholarcommons.usf.edu/etd/780.

Ndlovu, L. (2019). A design based research on students' understanding of quadratic inequalities in a graphing calculator enhanced environment. Dissertation presented for the degree of Doctor of Philosophy, Stellenbosch University, Stellenbosch.

Ndlovu, M. (2014). The effectiveness of a teacher professional learning programme: The perceptions and performance of mathematics teachers. Pythagoras, 35(2) Art \#237, 10 pages. https://doi.org/10.4102/pythagoras.v35i2.237

Oregon Department of Transportation Research Section (DTRS). (2010). Guide to transcribing and summarizing oral histories: Historic Columbia River highway oral history project. Salem, OR: DTRS.

Parrot, M.A.S., \& Leong, K.E. (2018). Impact of using graphing calculator in problem solving. International Electronic Journal of Mathematics Education, 13(3), 139-148. https://doi.org/10.12973/iejme/2704

Patton, M.Q. (2002). Qualitative research \& evaluation methods (3rd edn.). London: Sage.

Rich, B.S. (1991). The effect of the use of graphing calculators on the learning of function concepts in precalculus mathematics. ProQuest Dissertations \& Theses Global database. 9112475 Ph.D. Ann Arbor, MI: The University of lowa. Retrieved from http://search. proquest.com/docview/303868313 accountid=28930.

Shahriari, R. (2019). The effect of using technology on students' understanding in calculus and college algebra. Theses and Dissertations. p. 3264. Retrieved from https://scholarworks.uark.edu/etd/3264
Tan, C. K, Harji, M.B and Lau, S. H (2011). Graphing Calculator for Probability Students: How Was It Perceived? IBIMA Publishing. IBIMA Business Review. Vol. 2011 (2011), Article ID 167702, 11 pages. http://www.ibimapublishing.com/journals/ (2011), Article ID 1677

Theodora, F.R.N. \& Hidayat, D. (2018). The use of realistic mathematics education in teaching the concept of equality. JOHME: Journal of Holistic Mathematics Education, 1(2), 104-113. https://doi.org/10.19166/johme.v1i2.913

Thomas, R.V. (2016). The effects of dynamic graphing utilities on student attitudes and conceptual understanding in college algebra. Theses and dissertations. p. 1569. Retrieved from http://scholarworks.uark.edu/etd/1569

Tsamir, P., \& Almog, N. (2001). Student's strategies and difficulties: The case of algebraic inequalities. Mathematics Education Science Technology, 32(4), 513524. https://doi.org/10.1080/00207390110038277

Tsamir, P., \& Bazzini, L. (2004). Consistencies and inconsistencies in student's solution to algebraic 'single- value' inequalities. Mathematics Education Science Technology, 35(6), 793-812. https://doi.org/10.1080/00207390412331271357

Tsamir, P., \& Reshef, M. (2006). Students' preference when solving quadratic inequalities. Center for Teaching - Learning of Mathematics Gale group, Thompson Corporation Company. Retrieved from http://findarticles.com/p/ articles/mi_mONVC/is_1_28/ai_n26986050/

Van den Heuvel-Panhuizen, M., \& Drijvers, P. (2014). Realistic mathematics education. In S. Lerman (Ed.), Encyclopedia of mathematics education (pp. 521-525). Dordrecht: Springer. https://doi.org/10.1007/978-94-007-4978-8_170

Verikios, P., \& Farmaki, V. (2010). From equation to inequality using a function-based approach. International Journal of Mathematical Education in Science and Technology, 41(4), 515-530. https://doi.org/10.1080/00207390903564611

Wareham, K. (2016). Calculators and mathematics achievement: What the NAEP mathematics results tell us. Paper presented on January 3 at the (14th) 2016 Hawaii International Conference on Education. Honolulu, HI.

Yeo, K.K.J. (2011). An exploratory study of primary two pupils' approach to solve word problems. Journal of Mathematics Education, 4(1), 9.

Yin, L.Y. (2005). Understanding student's quadratic inequality misconception through an in-depth interview. Makalah disajikan dalam 3. International Qualitative Research Convention 2005. Qualitative Research Experience across Discipline, pp. 31-45. Universiti Teknologi Malaysia \& Qualitative Research Association of Malaysia: Sofitel Palm Resort, Senai, Johor, Malaysia. 
Appendix 1: Memorandum.

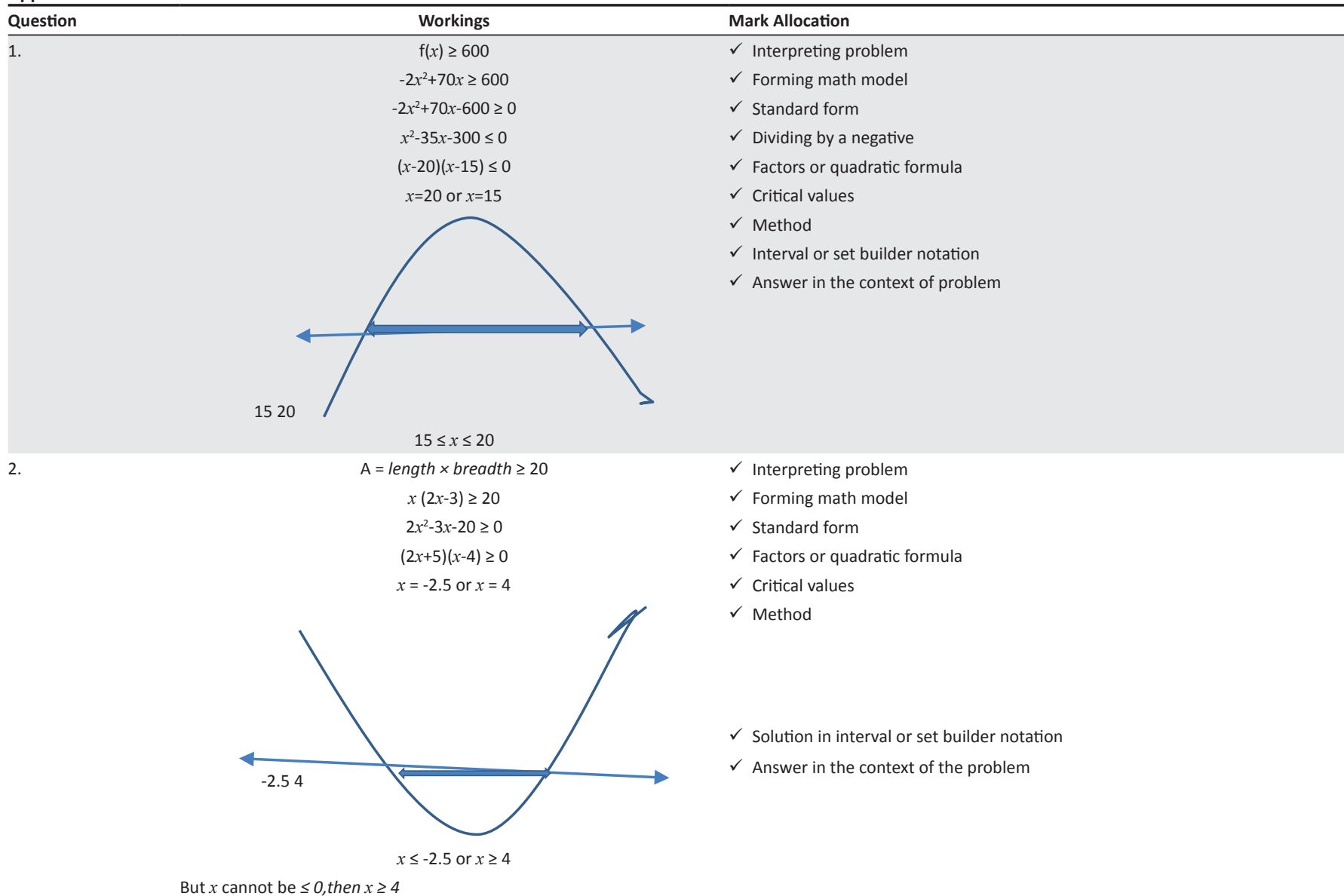

